\title{
Accessory breast poorly differentiated adenocarcinoma with positive HER2 gene amplification: A case report
}

\author{
Dinesh Francis Balasingam ${ }^{*}$, Ramesh Thangaratnam, Joel Sateeish Kumar \\ Department of General Surgery, Serdang General Hospital, Kajang, Selangor, Malaysia; \\ ${ }^{\#}$ Corresponding Author: dineshfrancis@hotmail.com
}

Received 29 November 2013; revised 28 December 2013; accepted 25 January 2014

Copyright (c) 2014 Dinesh Francis Balasingam et al. This is an open access article distributed under the Creative Commons Attribution License, which permits unrestricted use, distribution, and reproduction in any medium, provided the original work is properly cited. In accordance of the Creative Commons Attribution License all Copyrights (C) 2014 are reserved for SCIRP and the owner of the intellectual property Dinesh Francis Balasingam et al. All Copyright (C) 2014 are guarded by law and by SCIRP as a guardian.

\section{ABSTRACT}

Background: Primary poorly differentiated adenocarcinoma of the accessory breast is rare. We report such a case in a 56-year-old Malaysian woman of Indian ethnicity. Case Presentation: An axillary swelling measuring $5 \times 5 \mathrm{~cm}$ on excisional biopsy revealed a poorly differentiated adenocarcinoma with positive HER2 gene amplification. Conclusion: Overall prognosis is similar to that of a carcinoma of the normal breast, therefore early diagnosis is imperative to ascertain curable status and improve prognosis.

\section{KEYWORDS}

\section{Accessory Breast; Breast Cancer; Accessory Breast Cancer; HER2 Gene}

\footnotetext{
"The corresponding author has the right to grant on behalf of all authors and does grant on behalf of all authors, a worldwide licence to the publishers and its licensees in perpetuity, in all forms, formats and media (whether known now or created in the future), to 1) publish, reproduce, distribute, display and store the Contribution, 2) translate the contribution into other languages, create adaptations, reprints, include within collections and create summaries, extracts and/or, abstracts of the contribution and convert or allow conversion into any format including without limitation audio, 3) create any other derivative work(s) based in whole or part on the on the contribution, 4) to exploit all subsidiary rights to exploit all subsidiary rights that currently exist or as may exist in the future in the contribution, 5) the inclusion of electronic links from the Contribution to third party material where-ever it may be located; and, 6) licence any third party to do any or all of the above. All research articles will be made available on an Open Access basis (with authors being asked to pay an open access fee The terms of such Open Access shall be governed by a creative common slicence-details as to which creative commons licence will apply to the research article are set out in our worldwide licence referred to above.

"Corresponding author.
}

\section{BACKGROUND}

The occurrence of accessory breast tissue is seen in 2 6 percent of the population [1] and that with carcinoma occurring primarily in this accessory tissue reported rarely, amounting to only 0.3 to 0.6 percent of all breast cancer cases $[2,3]$. We report a rare case of a poorly differentiated adenocarcinoma of the accessory breast with positive HER2 gene amplification.

\section{CASE REPORT}

This 56 year post menopausal Malaysian lady of Indian ethnicity initially presented to a private institution for a painful axillary swelling that has been present for the past 6 months. This lady attained puberty at the age of 15 and she became menopausal 11 years ago. She has 4 children, who were all breast fed. She has never consumed oral contraceptives neither has she been on hormone replacement therapy. Her co-morbids include Mellitus and Bronchial Asthma.

On examination of the axillary during her visit to the private institution, they found a mass measuring $5 \times 6 \mathrm{~cm}$ with no overlying skin changes. A bilateral mammogram was done which revealed a BIRADS 2 lesion of the ipsilateral breast suggestive of a fibroadenoma.

Therefore it was decided to proceed with an incisional biopsy. The histopathology was reported as containing malignant large cell tumour infiltrates (Figure 1) in favour of a metastatic poorly differentiated adenocarcinoma.

Subsequently referred to the General Hospital, where a Computer Tomography Scan of the Head Neck, and Thorax was done which revealed multiple cervical and axillary lymphadenopathy without a significant primary 
lesion. In view of the histopathological findings being in favour of a metastatic poorly differentiated adenocarcinoma, we proceeded with an OGDS and Colonoscopy to further investigate for a primary lesion only to reveal normal investigative findings.

Finally it was decided to proceed with a PET-scan (Figure 2), which showed multiple FDG-avid left axillary lesions suspicious of metastatic lymph node disease and the primary lesion indeterminate.

Consequently an excision biopsy of the axillary mass was done, histopathologically reported as a poorly differrentiated adenocarcinoma with positive HER2 gene amplification.

She was consequently referred to the oncologist for adjuvant chemotherapy, which she responded well to.

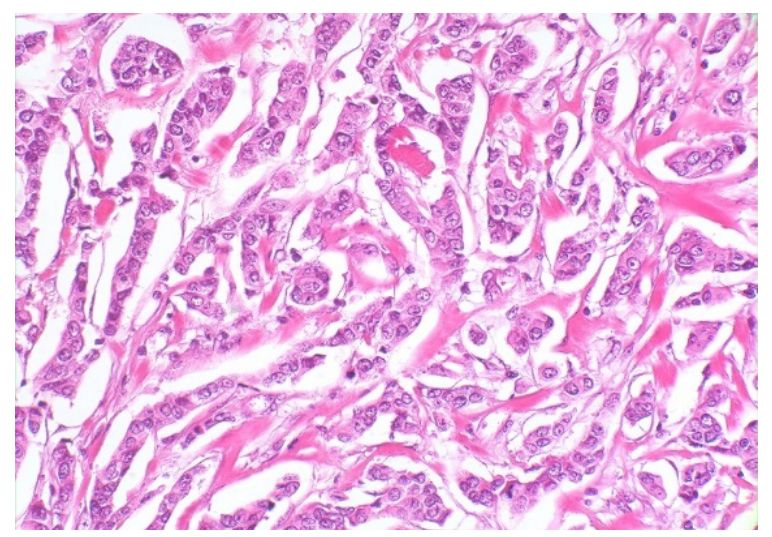

Figure 1. Malignant large cell tumourinfiltrates under 100 $\mathrm{nm}$ magnification.

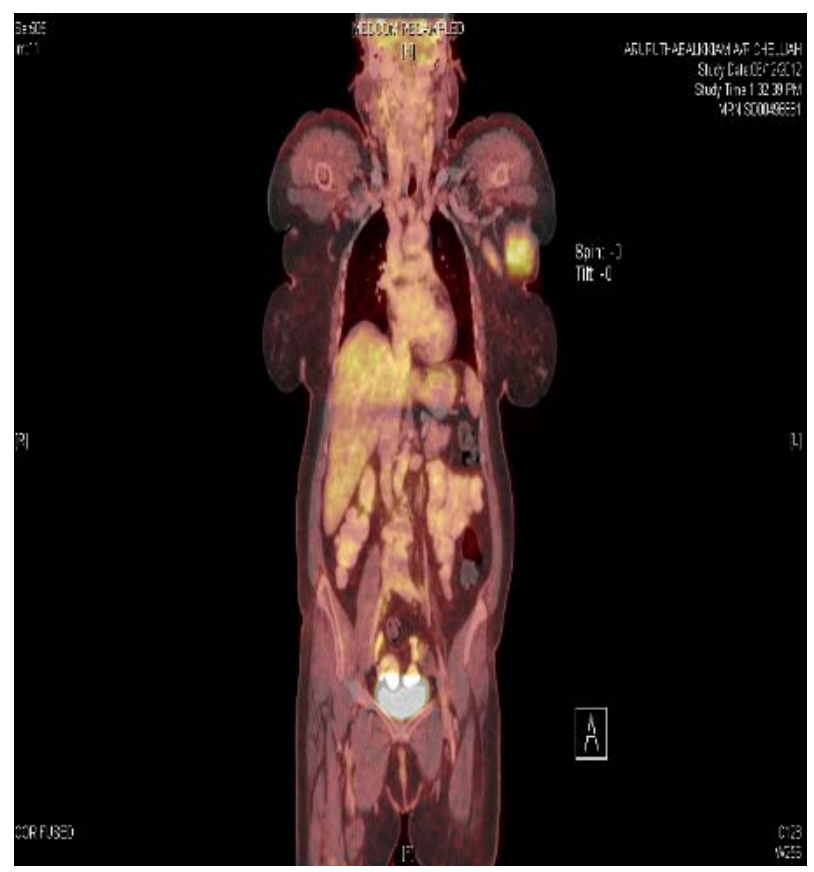

Figure 2. PET-scan revealing multiple FDG-avid left axillary lesions suspicious of metastatic lymph node disease.

\section{DISCUSSION}

Accessory breast tissue occurs in 2 - 6 percent of the general population [4] and the occurrence of a primary malignancy arising from this tissue is rare [1]. This accessory breast is the consequence of partial regression of the primitive milk streak that develops in the embryo [5], the commonest location being the axilla [4]. Being breast tissue, it is physiologically susceptible to homeostatic hormonal controls [6] and tends to develop during puberty and become apparent during pregnancy [5].

These accessory breasts associated with pathological changes such as mastitis, fibroadenoma, cystosarcoma, carcinoma, and duct hyperplasia have been reported, as described by Goyal S. et al. [4]. Primary accessory breast cancer is a rare form of breast cancer, in which this case reports a poorly differentiated adenocarcinoma with positive HER2 gene amplification.

Devine et al. describes that the most common morphological variant is that of the invasive ductal carcinoma type.

The overall prognosis is basically similar to that of breast cancer. Giron G. et al. mentions that the likelihood of an accessory breast malignancy being metastatic is much higher, being in close proximity with the axillary lymph node basin [7] hence the findings of multiple cervical and axillary lymphadenopathy described in this case.

Some authors recommended radical ipsilateral mastectomy if regional lymph nodes are involved, however Evans and Guyton [8,9] have concluded that ipsilateral mastectomy in addition to axillary lymph node dissection was not superior to local excision with node dissection.

This case was consequently referred to the oncologist for adjuvant chemotherapy and also referred to Breast and Endocrine Unit for opinion on a Mastectomy on the ipsilateral side. The Breast and Endocrine unit concluded that there was no need for a mastectomy as the PET-scan did not show any disease arising from the breast.

It is stated that tumours with HER2 gene amplification respond well to trastuzumab (Herceptin) and taxanechemotherapy, with the standard duration of treatment being one year $[8,10]$. But latest trials $[9,10]$ have proven the efficacy of T-DM1 (ado-trastuzumabemtansine; Kadcyla) in the treatment of metastatic breast cancers with HER2 gene amplification.

\section{CONCLUSION}

Overall prognosis is similar to that of a carcinoma of the normal breast, therefore early diagnosis is imperative to ascertain curable status and improve prognosis. Triple assessment is vital in any breast cancer for accurate diagnosis of any patients presenting with an axillary swelling. 


\section{CONSENT}

Written informed consent was obtained from the patient for publication of this case report and any accompanying images.

\section{COMPETING INTERESTS}

The authors declare that they have no competing interests.

\section{AUTHORS' CONTRIBUTIONS}

DFB drafted the manuscript. RT was clinically responsible for the patient's care. JSK was responsible for pathology.

\section{REFERENCES}

[1] Gutermuth, J., Audring, H., Voit, C. and Haas, N. (2006) Primary carcinoma of ectopic axillary breast tissue. Journal of the European Academy of Dermatology and Venereology, 20, 217-221.

http://dx.doi.org/10.1111/j.1468-3083.2005.01362.x

[2] Dhebri, A., Shah, N., Sripadam, R. and Arora, P.K. (2012) Skin lesion in axilla: An unusual presentation of invasive lobular carcinoma of breast. BMJ Case Reports.

[3] Youn, H.J. and Jung, S.H. (2009) Accessory breast carcinoma. Breast Care, 4, 104-106. http://dx.doi.org/10.1159/000210638
[4] Goyal, S., Puri, T., Gupta, R., Julka, P.K. and Rath, G.K. (2008) Accessory breast tissue in axilla masquerading as breast cancer recurrence. Journal of Cancer Research and Therapeutics, 4, 95-96.

http://dx.doi.org/10.4103/0973-1482.42258

[5] Devine, C., Carol-Ann, C., Deb, R. and Agrawal, A. (2013) Invasive lobular carcinoma arising in accessory breast tissue. World Journal of Surgical Oncology, 11, 47. http://dx.doi.org/10.1186/1477-7819-11-47

[6] Azuma, T., Yamamoto, K., Kobayashi, T. and Nakano, H. (1997) Accessory breast cancer: A case report of carcinoma originating from aberrant breast tissue in the axillary region. Journal of Breast Cancer, 4, 49-52.

[7] Giron, G., Friedman, I. and Feldman, S. (2004) Lobular carcinoma in ectopic axillary breast tissue. The American Surgery, 70, 312-315.

[8] Evans, D.M. and Guyton, D.P. (1995) Carcinoma of the axillary breast. Journal of Surgical Oncology, 59, 190195. http://dx.doi.org/10.1002/jso.2930590311

[9] Brufsky, A.M., et al. (2013) EMILIA trial: T-DM1 in metastatic breast cancer. http://www.onclive.com/peer-exchange/MBC-challenges/ EMILIA-Trial-T-DM1-in-Metastatic-Breast-Cancer

[10] National Cancer Institute (2012) Treatment options for HER2-positive breast cancer expand and evolve. NCI Cancer Bulletin, 9.

http://www.cancer.gov/ncicancerbulletin/101612/page2 